Special Issue of the 7th International Advances in Applied Physics and Materials Science (APMAS 2017)

\title{
Investigation of Mechanical and Thermal Properties of Waste EPDM and Polypropylene Mixtures
}

\author{
H. DemireR ${ }^{a}$, İ. KARTAL ${ }^{a, *}$, K. ÜNLÜ ${ }^{b}$ AND K. BÜYÜKKAYA ${ }^{c}$ \\ ${ }^{a}$ Marmara University, Faculty of Technology, 34720 Istanbul, Turkey \\ ${ }^{b}$ Ford Otosan Gölcük, 41120 Kocaeli, Turkey \\ ${ }^{c}$ Giresun University, 28049 Giresun, Turkey
}

\begin{abstract}
Automotive sector was considered as a sector since polypropylene was often used with ethylene propylene diene monomer (EPDM) as a mixture. EPDM rubber is characterized by wide range of applications. The aim of this study is to investigate the reusability of EPDM wastes. 10, 20, 30, 40 and $50 \mathrm{wt} \%$ ground EPDM powders were mixed with polypropylene (PP) matrix by extrusion method. Test specimens were prepared out of those mixtures by injection moulding. Tensile, the Izod impact, hardness, density, heat deflection, and the Vicat softening point tests were performed on the specimens. Tensile strength, force at break, $E$ modulus, hardness, heat deflection and the Vicat softening temperature values decreased with the increasing ground EPDM content in polypropylene matrix. However, the Izod impact and elongation at break values increased.
\end{abstract}

DOI: 10.12693/APhysPolA.134.257

PACS/topics: EPDM waste, recycling, polypropylene

\section{Introduction}

Plastics materials have been used in a wide spectrum ranging from simple daily applications to complex high technology applications. Nowadays, the use of plastics has exceeded the use of metals and ceramics by volume. As a result of this rapid expansion in usage, plastics' wastes have become a real problem to solve. Plastics' wastes pose an important threat for environment as with other consumed materials. Recycling of plastics' wastes has great importance for both economy and environment [1-4]. EPDM rubber is an elastomer which is characterized by wide range of applications. Processing and usage of this material leaves a considerable amount of waste. However, this material is not directly recycled due to its thermoset structure and generally used as a fuel in cement sector. This means an important economic loss [5-7]. There are two methods of grinding rubber-like materials such as EPDM for recycling purposes. These are grinding at room temperature and grinding by cooling with liquid nitrogen. Although fine sized powders are obtained by liquid nitrogen grinding method, investment and operation costs are higher $[8,9]$. The aim of this study is to investigate the reusability of EPDM wastes. $10,20,30,40$, and $50 \mathrm{wt} \%$ ground EPDM powders were mixed with PP matrix by extrusion method. Test specimens were prepared out of those mixtures by injection moulding. Tensile, the Izod impact, hardness, density, heat deflection and the Vicat softening point tests were performed on the specimens.

*corresponding author; e-mail: ilyaskartal@marmara.edu.tr

\section{Materials and method}

\subsection{Materials}

In this study, homopolymer polypropylene (PP MH418 polymer known as Petkim's petoplen) was used as matrix material. The EPDM rubber was specially manufactured by Standard Profile in the form of plates about $15 \mathrm{~mm}$ thick. The EPDM rubber is essentially the same as the material used by the Standard Profile Company in the production of automotive door and window sealing systems. Polyethylene wax OX.PE WAX LE 262 produced by Innospec Leuna was supplied by ERAL Turkey to facilitate processing as a lubricant. The IRGANOX 1010 antioxidant (supplied by the Ciba Turkey) was used to minimize any possible oxidation during the mixing in the extruder and during the injection molding.

\subsection{Preparation of test specimens}

EPDM sheets were produced under the same curing conditions from the EPDM formulation used in automotive door and window sealing systems. The surface of this sheet material was rubbed with a rotating wire brush attached to the grinding motor to obtain ground powders. Subsequently, ground EPDM powders less than $700 \mu \mathrm{m}$ in diameter were used in the preparation of blends. As a natural consequence of the EPDM rubber powder production method, EPDM powders appeared to be in quite different in size. Typical images of EPDM powders obtained from light microscopy are given in Fig. 1. As can be seen from the photographs obtained from the light microscope, small sized powders are present together with the larger sized powders. In addition, the EPDM part of the blends appears to be very large in size due to the tendency to aggregate through the electrostatic effects. EPDM and PP were weighed in accordance with 


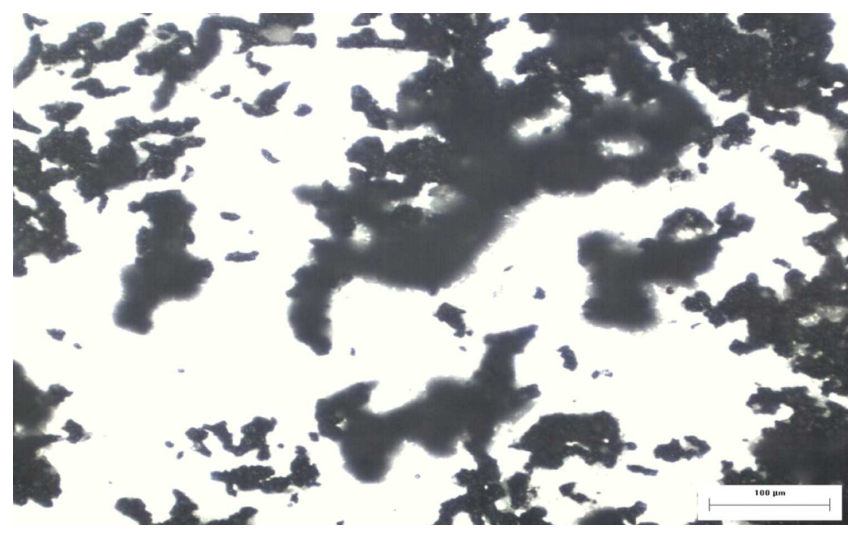

Fig. 1. Typical images of EPDM powders obtained from light microscope.

the weight percent mixture ratios initially set out in Table I. 10, 20, 30, 40 and $50 \mathrm{wt} \%$ ground EPDM was mixed with PP matrix by extrusion method. To these mixtures there were also added $1 \%$ of a lubricant and $0.2 \%$ of antioxidant. Test specimens were prepared out of those mixtures by injection moulding.

$\mathrm{PP} / \mathrm{EPDM}$ mixing ratios

TABLE I

\begin{tabular}{c|c|c|c|c|c|c}
\hline \hline Group & 1. & 2. & 3. & 4. & 5. & 6. \\
\hline PP [wt\%] & 100 & 90 & 80 & 70 & 60 & 50 \\
EPDM [wt\%] & 0 & 10 & 20 & 30 & 40 & 50
\end{tabular}

Results of density and mechanical tests of PP/EPDM

\subsection{Characterization}

Tensile tests were carried out according to EN 12814-1 and using an Instron 1011 model universal testing machine at a strain rate. The Izod impact tests were performed according to EN ISO 180 using an IM.01 model impact testing equipment. For scanning electron microscopy (SEM) analysis, JEOL JSM-5910LV model SEM was used at $10 \mathrm{kV}$. A Leica DMLP model microscope was used to get the light microscopy images of ground EPDM powders. Heat deflection temperature (HDT) and the Vicat softening point were determined by using a Ceast 6505 model testing equipment following standards ISO 307 and ISO 75, respectively. Shore D hardness test was carried out using a Zwick model equipment.

\section{Results and discussion}

The test results of the samples obtained from $\mathrm{PP}+$ EPDM mixtures are given in Table II and Fig. 2. The effect of ground EPDM content on the density and mechanical properties of the PP/EPDM mixtures was given in Table II. Tensile strength, $E$ modulus and hardness decreased with the increasing ground EPDM content. With the increasing ground EPDM content, elongation at break and the Izod impact strength increased. Since the EPDM is well known for its toughness, improved impact properties are expected in the case of $\mathrm{PP}$ matrix. As expected, the presence of EPDM caused a considerable decrease in the density of mixtures. These findings were, to a certain extent, in line with the inclusion of rubbery phase in polymeric matrices [3].

TABLE II

\begin{tabular}{c|c|c|c|c|c|c}
\hline \hline wt\% EPDM & $\begin{array}{c}\text { Tensile } \\
\text { strength [MPa] }\end{array}$ & $E$ modulus [MPa] & $\begin{array}{c}\text { Elongation } \\
\text { at break [\%] }\end{array}$ & $\begin{array}{c}\text { Hardness, } \\
\text { shore D }\end{array}$ & Density $\left[\mathrm{g} / \mathrm{cm}^{3}\right]$ & $\mathrm{Izod}\left[\mathrm{J} / \mathrm{m}^{2}\right]$ \\
\hline 0 & 21.97 & 169.08 & 20.73 & 70.6 & 0.9 & 3 \\
10 & 20.65 & 158.89 & 22.42 & 66.4 & 0.895 & 3.2 \\
20 & 19.44 & 148.53 & 24.53 & 65.4 & 0.89 & 3.8 \\
30 & 17.9 & 145.38 & 25.49 & 63.6 & 0.886 & 4.2 \\
40 & 14.02 & 110.78 & 27.77 & 61.6 & 0.884 & 4.9 \\
50 & 13.14 & 96.57 & 31.25 & 58 & 0.88 & 7.4
\end{tabular}

TABLE III

Vicat temperatures and HDT of the PP/EPDM mixtures

\begin{tabular}{c|c|c}
\hline \hline $\mathrm{wt} \%$ EPDM & Vicat temperature $\left[{ }^{\circ} \mathrm{C}\right]$ & HDT $\left[{ }^{\circ} \mathrm{C}\right]$ \\
\hline 0 & 100 & 89 \\
10 & 91 & 81 \\
20 & 79 & 79 \\
30 & 66 & 64 \\
40 & 60 & 58 \\
50 & 58 & 52
\end{tabular}

Table III shows the results of the Vicat softening point and heat deflection temperature measurements of the $\mathrm{PP} / \mathrm{EPDM}$ mixture. With the increase of ground EPDM content, the Vicat temperature decreased to about $40^{\circ} \mathrm{C}$. Again, with the increase of ground EPDM content, HDT decreased to about $35^{\circ} \mathrm{C}[5]$.

SEM microphotographs of PP/EPDM were presented in Fig. 2. Increasing ground EPDM content in the PP was seen clearly in SEM microphotographs.

\section{Conclusions}

When the mechanical properties of PP and ground EPDM mixtures were investigated, it was clearly observed that the tensile strength, modulus, shore D hardness, density, HDT and the Vicat values decreased while the Izod impact strength and breaking extension values increased. These results are 

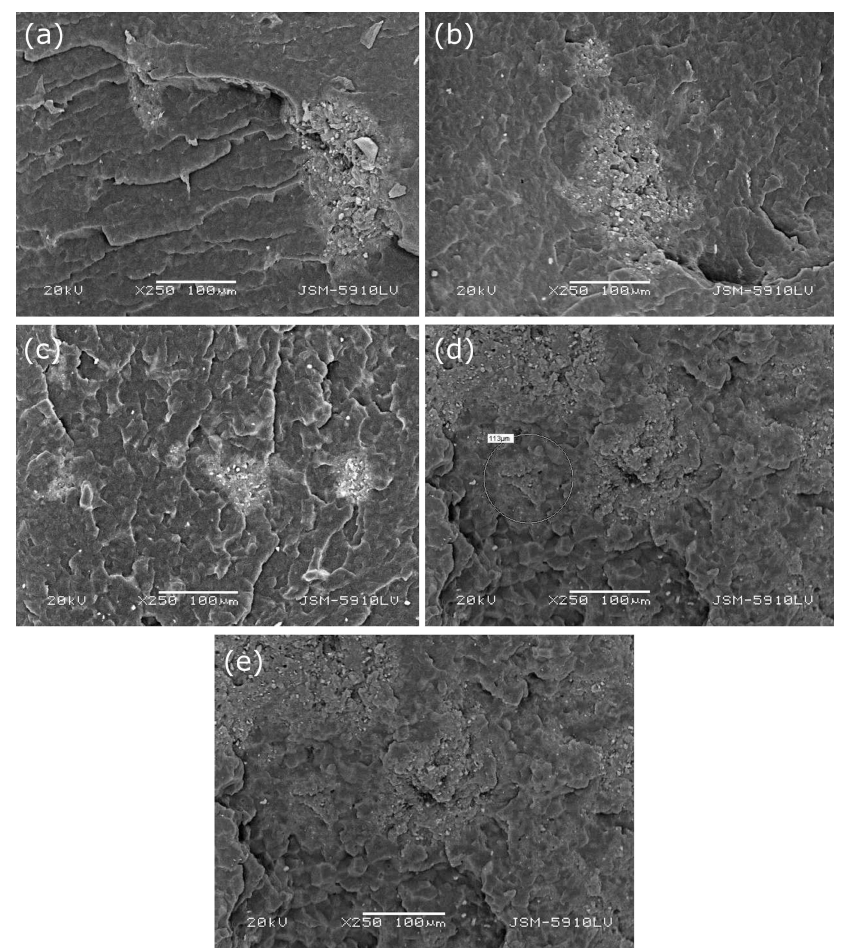

Fig. 2. SEM images of the PP/EPDM mixtures (a) $10 \%$, (b) $20 \%$, (c) $30 \%$, (d) $40 \%$, (e) $50 \%$.

the results that should normally appear in the $\mathrm{PP}+\mathrm{EPDM}$ mixtures when the mechanical properties of EPDM are taken into account. EPDM is a synthetic rubber, soft and flexible material in nature.
The hardness and modulus of EPDM are lower than PP. On the other hand, the values of yield and elongation at break are quite high. Since the EPDM powder used in this study cannot be obtained in very small dimensions, the desired elongation values could not be reached. The fact that the size of the EPDM powders is large and, in addition, the tendency of the EPDM powders to agglomerate together prevents the formation of a fine mixture between the PP and EPDM phases. In such a mixture, the EPDM phase must be dispersed in the matrix phase in a very fine fashion. Since the room temperature grinding was preferred in this study, inevitably coarser powders were obtained.

\section{References}

[1] D. Threadingham et al., Ullmann's Encyclopedia of Industrial Chemistry, 2000.

[2] W.H. Xiao, S.Q. Huang, J. Tao, J. Appl. Polym. Sci. 92, 357 (2004).

[3] C. Jacob, S. Bhowmick, J. Appl. Polym. Sci. 82, 3304 (2001).

[4] K. Aoudia, S. Azem, N.A. Hocine, M. Gratton, V. Pettarin, S. Seghar, Waste Manag. 60, 471 (2017).

[5] C.B. Bucknall, Toughened plastics, Applied Science Publishers, Ltd., London 1977.

[6] M. Koleva, Ch. Betchev, A. Zheglova, in: Advances in Composite Materials, Ed. P. Těšinová, IntechOpen, Rijeka 2011, Ch. 1.

[7] E.L. Rodriguez, Polym. Eng. Sci. 28, 22 (1988).

[8] B. Yesilata, Y. Isiker, P. Turgut, Constr. Build. Mater. 23, 1878 (2009).

[9] H.A. Khalid, I. Artamendi, Eng. Sustainabil. 157, 37 (2004). 